\title{
COMPORTAMENTO DO MOVIMENTO OCULAR EM QUATRO TIPOS DIFERENTES DE TAREFAS DE LEITURA ${ }^{1}$
}

\section{EYE MOVEMENT BEHAVIOUR ACROSS FOUR DIFFERENT TYPES OF READING TASK}

\author{
Arnt Lykke JAKOBSEN ${ }^{2}$ \\ Kristian Tangsgaard Hvelplund JENSEN ${ }^{3}$ \\ Tradução de: Tânia LIPARINI CAMPOS ${ }^{4}$
}

\begin{abstract}
Resumo: Um grupo de seis tradutores profissionais e outro de seis estudantes de tradução leram quatro textos jornalísticos sobre o mesmo assunto enquanto tiveram seus movimentos oculares rastreados. Os dois primeiros textos foram lidos com dois propósitos de leitura distintos, quais sejam, (a) para compreensão e (b) para tradução subsequente. Cada um dos outros dois textos foi lido para que houvesse, simultaneamente, (c) uma tradução à prima vista e (d) uma tradução escrita. Observouse que os tradutores profissionais foram mais rápidos que os estudantes. Em ambos os grupos, o tempo de execução da tarefa, a frequência de fixações, o tempo total de olhar (gaze) na tela e a duração média das fixações revelaram uma progressão consistente e linear de uma tarefa para a outra. Na última tarefa, relativa à tradução escrita, constatou-se que a distribuição da atenção visual foi maior no textofonte entre os estudantes e maior no texto-alvo entre os tradutores profissionais.
\end{abstract}

Palavras-chave: Leitura. Tradução. Compreensão. Produção. Rastreamento ocular.

\section{Fundamentação teórica}

Os movimentos oculares durante a leitura vêm sendo bastante estudados há décadas (cf. JUST; CARPENTER, 1980; RAYNER; POLLATSEK, 1989; RAYNER, 1998; HYÖNÄ et al., 2003; RADACH et al., 2004), já havendo documentação convincente acerca de diversos fatos básicos relativos a esses movimentos. Hoje se sabem: a duração e a extensão típica de uma sacada; a duração típica de uma fixação; e fatores que afetam a duração de uma fixação, como a familiaridade com uma palavra (WILLIAMS; MORRIS, 2004), a previsibilidade de uma palavra (FRISSON et al., 1999), o tamanho e a complexidade de uma palavra (KLIEGL et al., 2004; BERTMAN; HYÖNÄ, 2003; RAYNER; DUFFY, 1986) e a ambiguidade lexical e/ou sintática (JUHASZ; RAYNER, 2003). O que ainda não se sabe muito bem é como a

\footnotetext{
${ }^{1}$ Agradecemos a Arnt Lykke Jakobsen a gentileza de ceder os direitos para a publicação desta versão traduzida. Referência do artigo original: JAKOBSEN, Arnt Lykke; JENSEN, Kristian Tangsgaard Hvelplund. Eye movement behaviour across four different types of reading task. Copenhagen Studies in Language, v. 36, p. 103$124,2008$.

${ }^{2}$ Copenhagen Business School

${ }^{3}$ Copenhagen Business School

${ }^{4}$ Professora adjunta do Curso de Tradução da Universidade Federal da Paraíba (UFPB). Tem doutorado em Linguística Aplicada, com ênfase em Estudos da Tradução, pela Universidade Federal de Minas Gerais (UFMG). E-mail: $\underline{\operatorname{tania} @ \text {,cchla.ufpb.br }}$
} 
leitura varia de acordo com o seu propósito ou de acordo com a maneira como é combinada com outras atividades linguísticas, como no caso da tradução oral e da tradução escrita.

Os focos principais das pesquisas sobre leitura têm sido o processamento lexical e a leitura de sequências curtas de palavras, ao passo que pouca atenção tem sido destinada ao comportamento do movimento ocular durante a leitura contínua, a leitura com objetivos distintos ou a leitura sob diferentes circunstâncias. Há muitos livros populares sobre os benefícios das estratégias de leitura dinâmica ou rápida, como o skimming (para detecção do assunto geral do texto) e o scanning (para identificação de uma informação específica), e da capacidade de adaptar a velocidade de leitura ao seu propósito. Todavia, há pouca pesquisa sobre tipos mais específicos de propósitos de leitura, sobre a leitura de tipos específicos de texto ou sobre a leitura para tradução.

Nosso objetivo e interesse foram estudar os efeitos sobre os movimentos oculares trazidos por instruções de leitura de um mesmo texto, ou de textos quase idênticos, com dois propósitos diferentes, quais sejam: para compreensão ou com a intenção de traduzir o texto. Também se buscou estudar quais diferenças haveria na atenção visual conferida a um texto a depender de a sua leitura ser acompanhada ou não por outras atividades linguísticas, como a sua verbalização em voz alta ou a sua tradução oral ou escrita. Consideramos que seria altamente interessante investigar, por meio de um rastreador ocular, a combinação, mais ou menos concomitante, entre leitura e tradução escrita e entre leitura e tradução oral.

Como somos oriundos de um universo de pesquisas do processo tradutório, estávamos particularmente interessados em observar, primeiramente, se seria possível detectar diferenças entre a leitura de um texto com propósitos genéricos, visando à compreensão de seu significado, e a leitura do mesmo texto (ou de um texto bem semelhante) com a expectativa de ter que o traduzir na sequência. Em segundo lugar, estávamos interessados em observar se a leitura de um texto nas condições supramencionadas resultaria em um nível de atenção visual diferente daquele encontrado durante uma tradução oral do texto que está sendo lido (i.e., tradução à prima vista). Por fim, estávamos interessados em observar o quanto os tradutores, trabalhando na modalidade escrita, prestariam atenção ao texto sendo traduzido (o texto-fonte) e ao texto sendo digitado (o texto-alvo) e em que medida a sua atenção visual seria semelhante àquelas identificadas nas outras tarefas. Se fossem encontradas diferenças, buscaríamos suas causas prováveis. No plano das ideias, já imaginávamos possíveis conclusões que poderiam ter consequências para a nossa prática pedagógica. 


\section{Configuração e desenho experimental}

Utilizou-se o rastreador ocular do tipo "remoto" Tobii 1750 para registrar os movimentos oculares de seis estudantes de tradução e de seis tradutores profissionais durante a leitura de quatro textos jornalísticos curtos em inglês - cada qual com cerca de 200 palavras sobre uma mesma notícia internacional - no contexto de quatro tarefas (cf. textos completos no apêndice A). Os textos foram exibidos em fonte Times Roman, tamanho 16, espaçamento duplo, em um monitor de LCD de 17" com resolução de 1280 x 1024 pixels. A distância média pretendida entre o tradutor e a tela foi de $60 \mathrm{~cm}$, não havendo suporte para a cabeça ou o queixo. Utilizaram-se os softwares Translog 2006 para exibir o texto na tela e Audacity para gravar os dados de fala (Tarefa 3).

Quando se realizam experimentos com um rastreador ocular do tipo "remoto", há certo risco de perder dados ou de obter dados com má qualidade. A vantagem significativa de não se usar uma placa de mordida ou um suporte para a cabeça ou o queixo é contrabalançada pelo risco de que os dados podem ser eventualmente imperfeitos, o que é particularmente crítico se forem necessárias medidas muito precisas. No conjunto de experimentos aqui apresentados, os quais envolveram leitura contínua de um texto e várias centenas de medições em cada tarefa, estimamos que uma imprecisão isolada não teria efeito crítico nas médias totais e, como se mostrou mais tarde, descartamos menos de $10 \%$ dos nossos dados brutos.

Várias ferramentas padrão foram utilizadas para medir a complexidade ortográfica, lexical e sintática dos quatro textos. Queríamos que os textos fossem autênticos, mas também comparáveis entre si na medida do possível. O número de caracteres nos quatro textos variou entre 1086 e 1117; o número de palavras, entre 187 e 197; e o comprimento médio da palavra, entre 4,35 e 4,87 caracteres. A diferença maior foi no número de sentenças $(8,8,7$ e 6$)$. A relação forma/item (type/token) variou entre 0,62 e 0,64. O número de palavras muito frequentes (K1) foi entre $76 \%$ e $79 \%$; e o percentual de palavras menos frequentes (K2-K20) ficou entre $17 \%$ e $18 \%$. Pelo índice de legibilidade SMOG, os textos ficaram entre os valores de 12,5 e 15. Além disso, como medida adicional para neutralizar eventuais efeitos de distorção causados por textos diferentes, fizemos um rodízio sistemático da combinação tarefa-texto, de forma que o participante $1 \mathrm{fez}$ a Tarefa 1 com o Texto 1 , a Tarefa 2 com o Texto 2 etc., enquanto o participante 2 fez a Tarefa 1 com o Texto 2, a Tarefa 2 com o Texto 3 etc. e assim por diante.

Devido à sucessão de quatro tarefas, sempre apresentadas na mesma sequência, envolvendo a leitura de textos semelhantes que reportavam o mesmo evento em uma 
linguagem similar, era de se esperar um efeito cumulativo de pré-ativação, ou priming (i.e., influência indesejada de um evento antecedente sobre um evento posterior, intencionado), de uma tarefa para a outra. Por causa desse efeito, esperávamos encontrar relativamente menos fixações (em palavras repetidas) - provavelmente também mais curtas nas últimas tarefas.

Solicitou-se aos participantes que todas as tarefas fossem realizadas na velocidade a que eles normalmente trabalham. Não foi imposta restrição de tempo, mas podemos considerar que tradução à prima vista (Tarefa 3) possui um padrão de velocidade inerente à atividade, o que pode ter automaticamente introduzido um elemento de pressão de tempo nessa tarefa. As tarefas foram as seguintes:

- Tarefa 1 (leitura para compreensão): foi uma tarefa simples de leitura na qual se solicitou aos participantes que lessem o texto "para compreensão" da forma como normalmente leriam esse tipo de texto. A tarefa era finalizada quando os participantes indicavam que haviam concluído a leitura. A compreensão do texto não foi testada em seguida;

- Tarefa 2 (leitura como preparação para traduzir): foi uma tarefa de leitura igual à Tarefa 1, mas, nesse caso, foi dada aos participantes a instrução de que traduziriam o texto após a sua leitura (embora de fato isso não tenha ocorrido);

- Tarefa 3 (leitura durante uma tradução oral - "tradução à prima vista"): foi uma tarefa na qual se exigiu que os participantes combinassem a leitura do texto com a produção de sua tradução oral para a L1 (dinamarquês). A tradução à prima vista é um gênero híbrido em que um texto escrito é lido e transformado pelo tradutor/intérprete em um texto oral. Todos os participantes tinham experiência prévia com esse gênero e entenderam imediatamente em que consistia a tarefa; e

- Tarefa 4 (leitura durante a digitação de uma tradução escrita): foi uma tarefa de tradução escrita tradicional da L2 para a L1. Como em todas as tarefas anteriores, o texto foi exibido no Translog, na tela do computador. Nessa tarefa, no entanto, a tradução escrita dos participantes também apareceu na tela do computador, em uma janela abaixo da janela na qual o texto-fonte estava sendo exibido. Para facilitar a análise dos dados do olhar, os participantes foram instruídos a rolar o texto-fonte apenas uma vez. Os acionamentos de teclas foram armazenados, no Translog, juntamente com os registros de tempo de cada evento, embora esses dados não sejam relevantes para a análise aqui apresentada. 
Em suma, as variáveis do desenho experimental foram as seguintes:

- variáveis independentes: duas modalidades distintas de leitura (para compreensão e com intenção de traduzir) e duas modalidades distintas de tradução (oral, à prima vista, e escrita). O par linguístico e a direção foram do inglês para o dinamarquês);

- variáveis dependentes: tempo de leitura (duração da tarefa), número de fixações, tempo total de duração do olhar (incluindo regressões), duração das fixações e transição entre as "áreas de interesse" (somente para a Tarefa 4); e

- variáveis controladas: materiais textuais, tipo de texto, tamanho de texto, perfil do tradutor, condições experimentais e ordem das tarefas.

\section{Análise dos dados}

Comparamos quatro medidas de cada uma das tarefas, quais sejam: (i) duração da tarefa; (ii) número total de fixações; (iii) duração total das fixações durante a execução da tarefa ("tempo total do olhar"); e (iv) duração média de fixações individuais. Além disso, para a Tarefa 4, analisamos, o número de transições entre a área do texto-fonte e a área do textoalvo.

\subsection{Duração da tarefa}

Em relação à duração da tarefa, observamos que, como esperado, o grupo dos tradutores profissionais, que inclui um intérprete, foi, em média, mais rápido em todas as tarefas do que o grupo de estudantes (cf. Tabela 1).

Tabela 1 - Duração média (em segundos) das tarefas realizadas pelos tradutores profissionais e pelos estudantes de tradução

\begin{tabular}{l|c|c}
\cline { 2 - 3 } & Profissionais & Estudantes de tradução \\
\hline Tarefa 1 & 40 & 61 \\
\hline Tarefa 2 & 57 & 103 \\
\hline Tarefa 3 & 154 & 204 \\
\hline Tarefa 4 & 771 & 945 \\
\hline
\end{tabular}


A duração média (tempo de leitura) da Tarefa 1 foi de $40 \mathrm{~s}$ (variação de $23 \mathrm{~s}$ a $59 \mathrm{~s}$ ) entre os tradutores profissionais e de $61 \mathrm{~s}$ (variação de $46 \mathrm{~s}$ a $84 \mathrm{~s}$ ) entre os estudantes de tradução. Como os textos tinham em torno de 200 palavras, isso significa que os profissionais leram cinco palavras por segundo (variação de 3 a 9) e os estudantes, três palavras por segundo (variação de 2 a 4).

A duração média da Tarefa 2 foi consideravelmente maior do que aquela da Tarefa 1. No caso, os profíssionais despenderam em média $57 \mathrm{~s}$ (variação de $48 \mathrm{~s} \mathrm{a} 79 \mathrm{~s}$ ) ${ }^{5}$, enquanto os estudantes de tradução, 103 s (variação de 71 s a 146 s).

A duração média da Tarefa 3 foi mais de duas vezes maior do que aquela da Tarefa 2. Houve variância considerável entre os participantes dentro dos dois grupos, mas os profissionais também foram consideravelmente mais rápidos do que os estudantes de tradução. A média foi de $154 \mathrm{~s}$ (variação de $99 \mathrm{~s}$ a $194 \mathrm{~s}$ ) entre os profíssionais e de $204 \mathrm{~s}$ (variação de 172 s a 246 s) ${ }^{6}$ entre os estudantes de tradução.

A maior diferença na duração se deu na Tarefa 4, que, no geral, durou cerca de cinco vezes mais do que a Tarefa 3. A duração média foi, para o grupo de tradutores profissionais, de $771 \mathrm{~s}$ (variação de $589 \mathrm{~s}$ a $982 \mathrm{~s})^{7}$ e, para o grupo de estudantes de tradução, de $945 \mathrm{~s}$ (variação de 683 s a 1161 s) ${ }^{8}$.

\subsection{Número de fixações}

A diferença de tempo nas execuções da Tarefa 1 e da Tarefa 2 implicou, para todos os participantes, uma diferença no número de fixações nas palavras dos textos. Os números médios de fixações para todos os participantes (tradutores profissionais e estudantes de tradução) foram 145 (variação de 66 a 232) na Tarefa 1223 (variação de 85 a 430) na Tarefa 2. As Figuras 1 e 2, fornecidas pelo software ClearView, mostram plotagens do olhar (gaze plot) típicas dessas duas tarefas.

\footnotetext{
${ }^{5}$ Excluiu-se um valor atípico, outlier, de 148 s. Caso esse valor fosse incluído, a duração média da leitura na Tarefa 2 subiria para $73 \mathrm{~s}$ entre os profissionais.

${ }^{6}$ Excluiu-se um valor atípico, outlier, de 542 s. Caso esse valor fosse incluído, a duração média da leitura na Tarefa 1 subiria para $261 \mathrm{~s}$ entre os estudantes.

${ }^{7}$ Excluiu-se um valor atípico, outlier, de 1364 s. Caso esse valor fosse incluído, a duração média da leitura na Tarefa 4 subiria para $869 \mathrm{~s}$ entre os profissionais.

${ }^{8}$ Excluiu-se um valor atípico, outlier, de 2609 s. Caso esse valor fosse incluído, a duração média da leitura na Tarefa 4 subiria para $1222 \mathrm{~s}$ entre os estudantes.
} 
Figura 1 - Plotagem do olhar no texto de um participante quando da execução da Tarefa 1

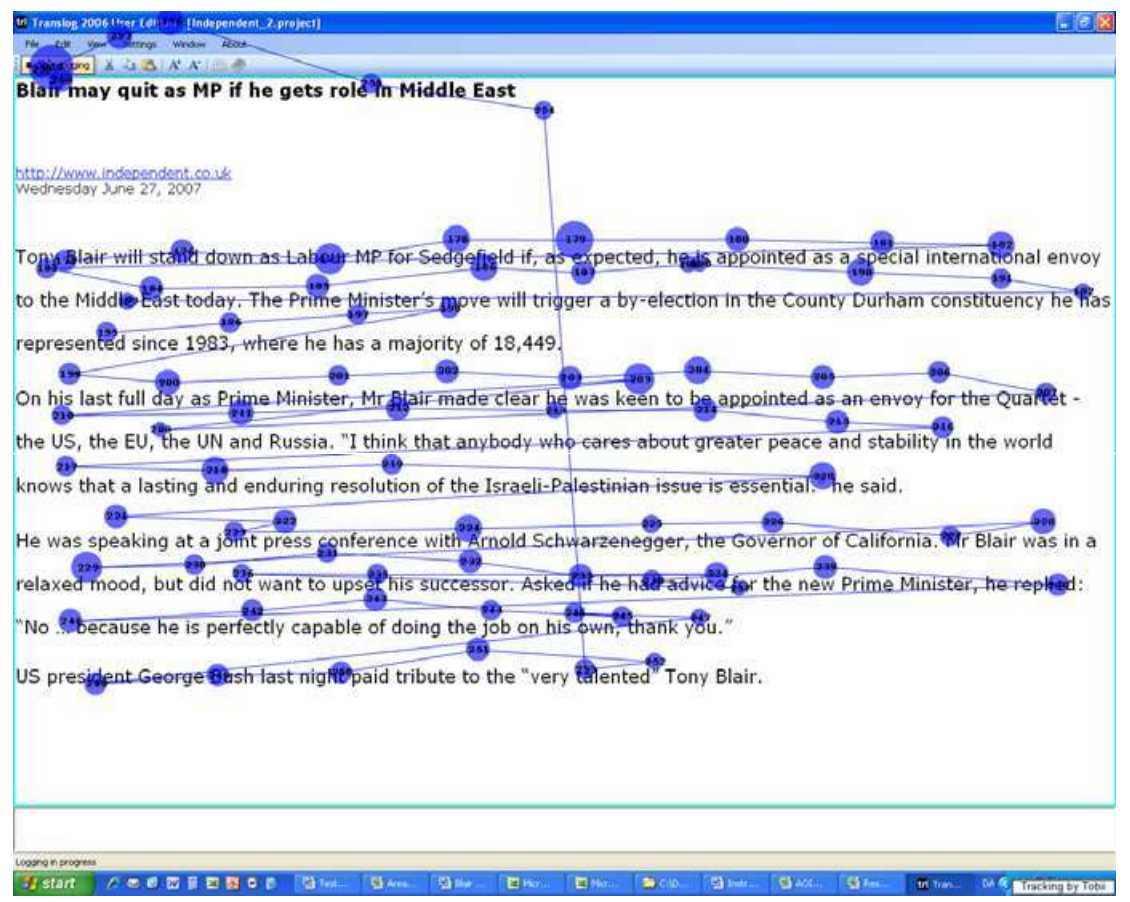

Figura 2 - Plotagem do olhar no texto de um participante quando da execução da Tarefa 2

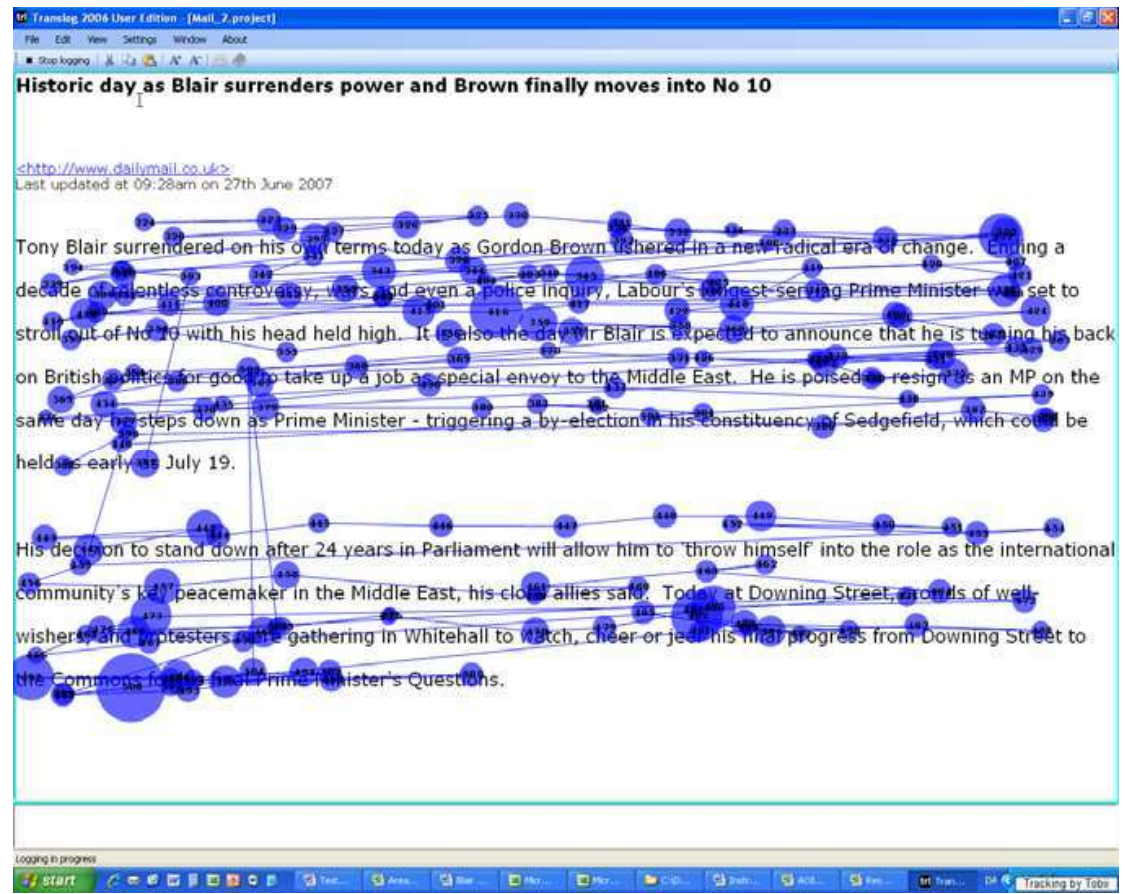

O número médio de fixações na Tarefa 3 foi de 520 (variação de 305 a 850) considerando todos os 12 participantes (cf. Figura 3, fornecida pelo software ClearView), ou seja, foi mais do que o dobro da média na Tarefa 2. O maior número de fixações ocorreu na 
Tarefa 4. A Figura 4, fornecida pelo software ClearView, é uma plotagem do olhar típica dessa tarefa e mostra um verdadeiro emaranhado de fixações.

Figura 3 - Plotagem do olhar no texto de um participante quando da execução da Tarefa 3

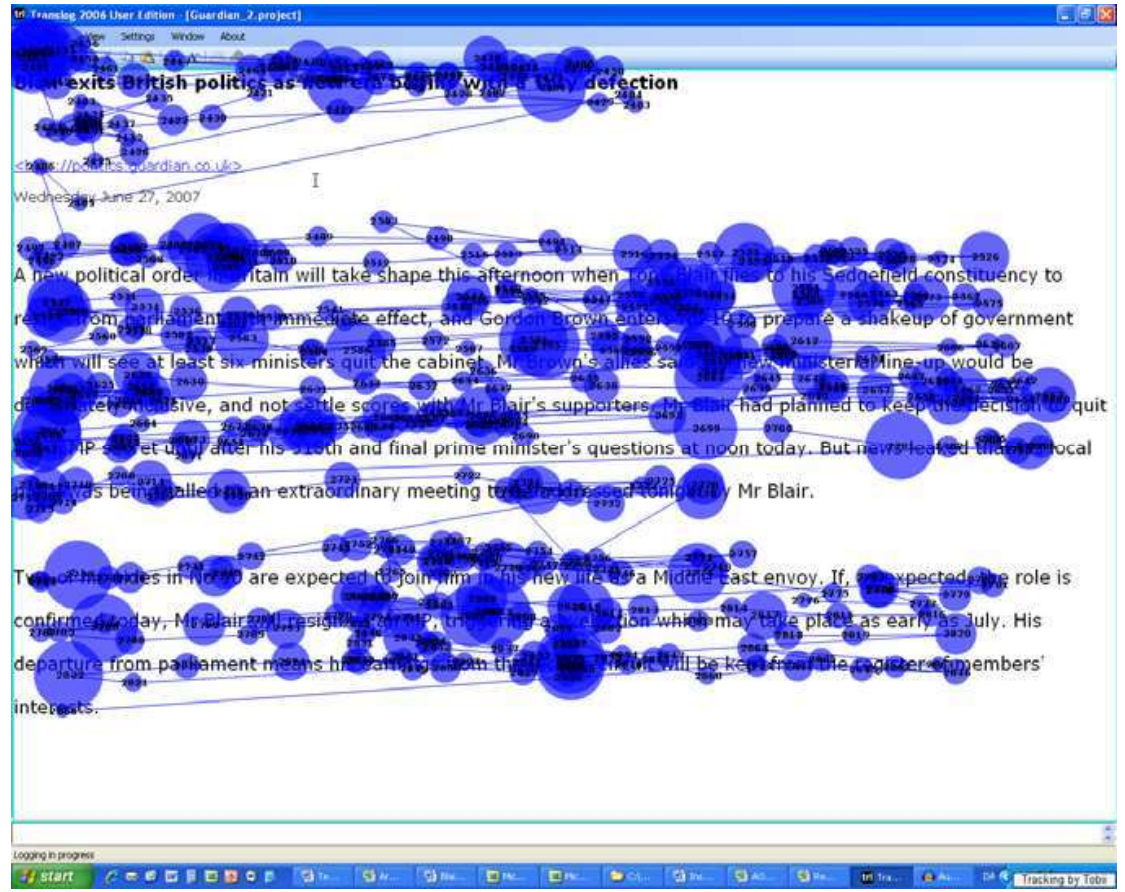

Figura 4 - Plotagem do olhar no texto-fonte e no texto-alvo de um participante quando da execução da Tarefa 4

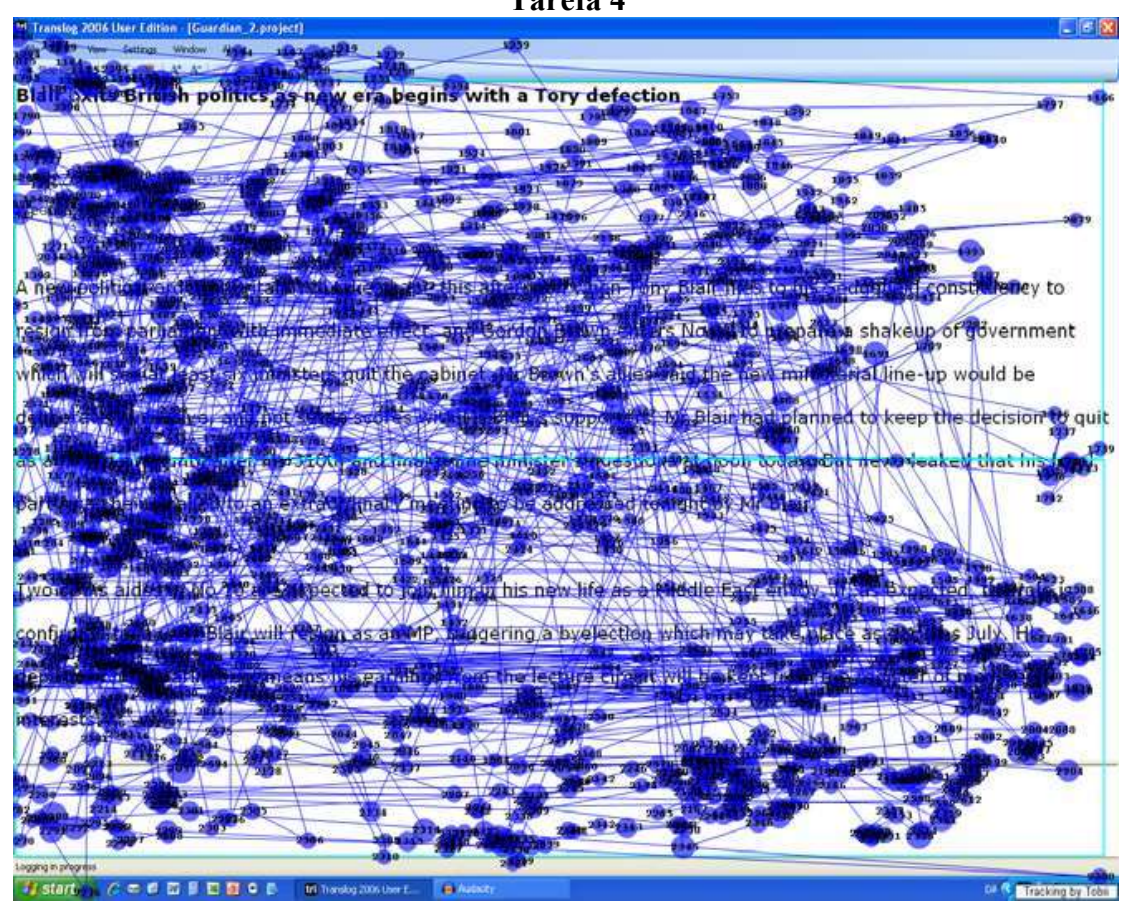


$\mathrm{Na}$ Tarefa 4, o número médio de fixações subiu para 1590 (variação de 1062 a 2680) ${ }^{9}$, em torno de três vezes o valor da Tarefa 3. Proporcionalmente, esse aumento no número de fixações foi menor do que o aumento na duração da tarefa, mas, ainda assim, o aumento foi bem considerável e muito maior do que o esperado.

Ao dividir a tela em "áreas de interesse" separadas, uma para o texto-fonte e outra para o texto-alvo, foi possível calcular o número de fixações em cada área e o número de transições de uma área para a outra. $\mathrm{Na}$ área do texto-fonte, o número médio de fixações foi de $708^{10}$. A atenção visual destinada ao texto-alvo envolveu ainda mais fixações do que no texto-fonte, com uma média de $882^{11}$.

\subsection{Duração do olhar}

A duração total das fixações durante a realização das quatro tarefas apresentou uma progressão semelhante àquela encontrada em relação à duração da tarefa e ao número de fixações. A média de todos os participantes foi de $30 \mathrm{~s}$ na Tarefa 1, aumentando para $40 \mathrm{~s}$ na Tarefa 2, $120 \mathrm{~s}$ na Tarefa 3 e $454 \mathrm{~s}$ na Tarefa 4, sendo $195 \mathrm{~s}$ na área do texto-fonte e $259 \mathrm{~s}$ na área do texto-alvo. Os dados estão resumidos por grupo na Tabela 2.

Tabela 2 - Duração média do olhar (em segundos) por tarefa entre os tradutores profissionais e entre os estudantes de tradução

\begin{tabular}{l|c|c}
\cline { 2 - 3 } & Profissionais & Estudantes de tradução \\
\hline Tarefa 1 & 29 & 31 \\
\hline Tarefa 2 & $33^{12}$ & 47 \\
\hline Tarefa 3 & 115 & 127 \\
\hline Tarefa 4 (área do texto-fonte) & 145 & 255 \\
\hline Tarefa 4 (área do texto-alvo) & 288 & 223 \\
\hline
\end{tabular}

O aumento na duração do olhar foi notavelmente consistente entre as quatro tarefas para todos os 12 participantes, como mostra a Figura 5.

\footnotetext{
${ }^{9}$ Desconsideraram-se um outlier inferior (723) e um valor outlier superior (5795). Caso fossem inclusos, a média seria de 1893.

${ }^{10}$ Se fossem inclusos os outliers, a média passaria para 895.

${ }^{11}$ Se fossem inclusos os outliers, a média passaria para 998.

${ }^{12} \mathrm{Se}$ fosse incluso um outlier, a média subiria para 51.
} 
Figura 5 - Distribuição relativa da duração do olhar entre as quatro tarefas realizadas pelos 12 participantes

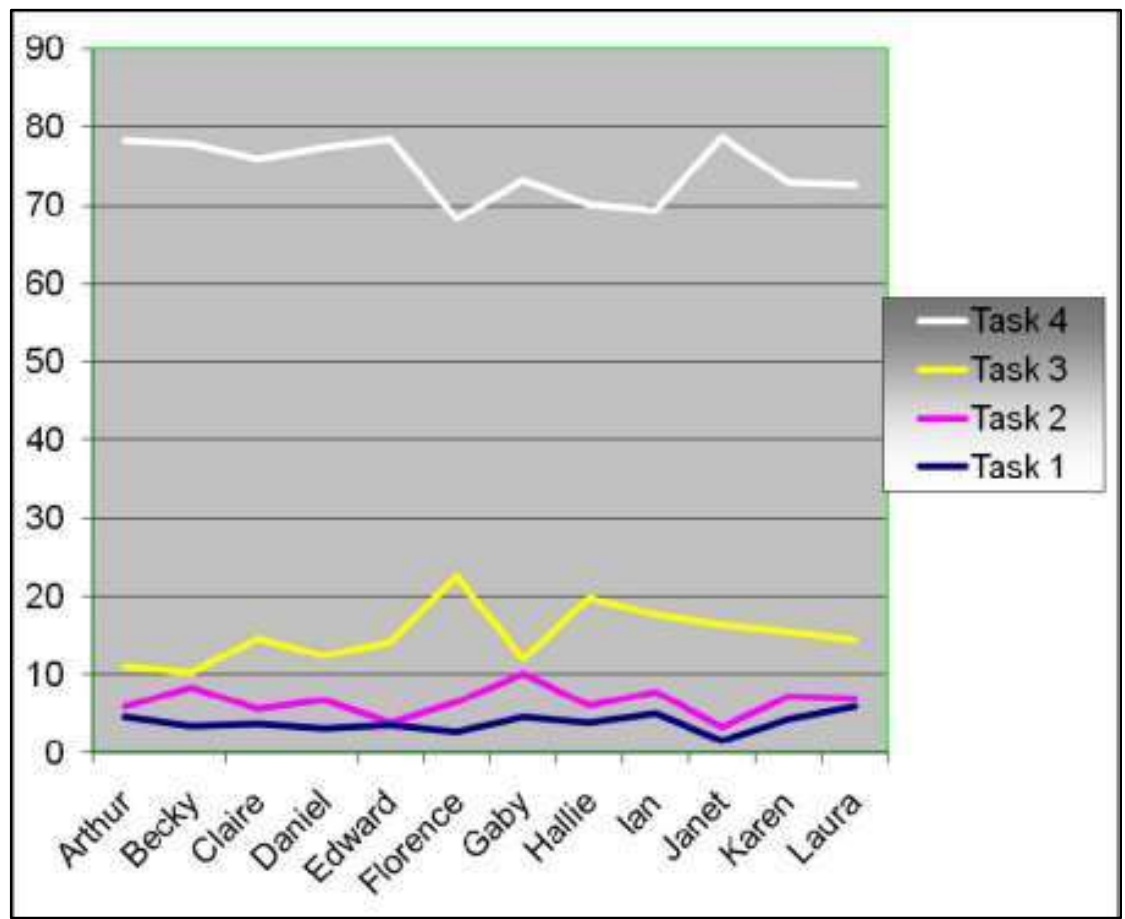

Ao comparar a duração da tarefa com a duração do olhar, foi possível calcular quanto do tempo total da tarefa os participantes usaram para olhar para a tela (Tabela 3). As sacadas duram geralmente entre 20 e 35 ms (RAYNER; POLLATSEK, 1989: 113) e constituem, portanto, 10 a $15 \%$ do tempo de leitura. Os valores percentuais na Tabela 3 deveriam, portanto, ter um aumento de 10 a 15\%. O fato de a diferença entre duração da tarefa e duração do olhar ter sido de apenas 50\% em alguns casos (para o grupo dos estudantes de tradução) sugere que, ou o olhar (gaze) dos estudantes saiu da tela com mais frequência do que no caso dos tradutores profissionais, ou que, por alguma razão, houve mais perda de dados do olhar nesse grupo.

Tabela 3 - Percentual da duração média do olhar em relação ao tempo total de tarefa realizada por grupo

\begin{tabular}{l|c|c|c|c}
\cline { 2 - 5 } & Profissionais & $\%$ & Estudantes de tradução & $\%$ \\
\hline Tarefa 1 & $29 / 40$ & 72,5 & $31 / 61$ & 50,8 \\
\hline Tarefa 2 & $33 / 57$ & 57,9 & $47 / 103$ & 45,6 \\
\hline Tarefa 3 & $115 / 154$ & 74,7 & $127 / 204$ & 62,3 \\
\hline Tarefa 4 (área do texto-fonte) & $145 / 771$ & 18,8 & $255 / 945$ & 27,0 \\
\hline Tarefa 4 (área do texto-alvo) & $288 / 771$ & 37,4 & $223 / 945$ & 23,6 \\
\hline
\end{tabular}




\subsection{Duração das fixações}

Estudos sobre fixações em palavras mostram que elas duram tipicamente entre $200 \mathrm{~ms}$ e 250 ms e que sua duração varia de acordo com uma série de parâmetros. No projeto Eye-toIT, financiado pela União Europeia, foi desenvolvido um aplicativo que ativa um alerta de tradução online se a fixação do usuário em uma palavra exceder certo limite de tempo. Essa funcionalidade se baseia na hipótese olho-mente (JUST; CARPENTER, 1980), segundo a qual há uma alta correlação entre fixações longas e esforço de processamento. Ao disponibilizar um alerta nesses casos, o objetivo é reduzir o esforço de processamento, acelerar o processo de tradução e, idealmente, melhorar a qualidade da tradução.

Em nossos dados, a variância entre os grupos não foi significativa, mas houve diferenças interessantes entre as tarefas. Nossos resultados estão resumidos na Tabela 4.

Tabela 4 - Duração média das fixações, em milissegundos, para todos os participantes por tarefa

\begin{tabular}{l|c}
\hline Duração da fixação $(\mathbf{m s})$ por tarefa & Média para todos os participantes \\
\hline Tarefa 1 & 205 \\
\hline Tarefa 2 & 205 \\
\hline Tarefa 3 & 235 \\
\hline Tarefa 4 (área do TF) & 218 \\
\hline Tarefa 4 (área do TA) & 259 \\
\hline
\end{tabular}

\subsection{Transições (Tarefa 4)}

Para o grupo de profissionais, o número médio de transições da área do texto-fonte para a área do texto-alvo (ou vice-versa) foi igual a 190 e, para o grupo de estudantes, foi igual a $259^{13}$. Se considerarmos que a duração média da tarefa foi de, respectivamente, $771 \mathrm{~s} \mathrm{e}$ 945 s para cada grupo, tem-se que tanto os tradutores profissionais como os estudantes de tradução fizeram em torno de uma transição a cada $4 \mathrm{~s}$.

\subsection{Análise estatística ${ }^{14}$}

Um teste $t$ pareado para os dados relativos ao número de fixações aponta que todas as diferenças médias entre as quatro tarefas (considerando-se todos os participantes) foi significativa. $\mathrm{O}$ aumento do número médio de fixações da Tarefa 1 para a 2 foi significativo, com $p<0,001, t=-5,558$ e $d f=11$. O aumento da média de fixações da Tarefa 2 para a 3

\footnotetext{
${ }^{13}$ Se fossem inclusos os outliers, a média subiria para 367.

${ }^{14}$ Gostaríamos de agradecer a assistência estatística de Selina Sharmin, da Universidade de Tampere.
} 
também foi significativo, com $p<0,01, t=4,485$ e $d f=11$. O aumento do número de fixações da Tarefa 3 para a 4 também foi significativo, com $p<0,01, t=-3,378$ e $d f=11$. Essas diferenças foram todas significativas independentemente de os outliers estarem inclusos ou não. Por fim, o aumento no número de fixações da Tarefa 3 para a 4 (considerando apenas a área do texto-fonte) também foi significativo, com $p<0,05, t=-2,671$ e $d f=11$. O aumento no número de fixações entre as duas áreas de interesse na Tarefa 4 não foi significativo. Nenhuma das diferenças observadas na duração total do olhar alcançou significância estatística.

O aumento da duração média da fixação da Tarefa 1 para a 3 e da Tarefa 2 para a 3 foram, ambas, próximas à significância, com $p=0,074(t=-1,978, d f=11)$ para o aumento da Tarefa 1 para a 3 e $p<0,05(t=3,025, d f=11)$ para o aumento da Tarefa 2 para a 3 . No entanto, o aumento na duração média da fixação entre as duas áreas de interesse na Tarefa 4 não foi significativo (assim como o aumento no número de fixações).

Uma análise de variância (ANOVA) unidirecional por grupo entre todas as tarefas mostrou que o número médio de fixações para os estudantes de tradução foi significativamente maior do que aquele para os profissionais, com $p<0,01, F_{1,10}=12,735$. A duração média das fixações registradas foi sistematicamente mais longa em todas as tarefas para o grupo de profissionais do que para o grupo de estudantes de tradução, mas essa diferença não alcançou significância. Para os dois grupos, as fixações na janela do texto-alvo, na Tarefa 4, foram mais longas $(259 \mathrm{~ms})$ do que aquelas na janela do texto-fonte $(218 \mathrm{~ms})$, mas essa diferença também não foi estatisticamente significativa. Não foi encontrada qualquer outra diferença significativa entre os grupos.

\section{Discussão dos resultados}

\subsection{Duração da tarefa}

O aumento no tempo de leitura da Tarefa 1 para a 2, em que a única diferença consistia na expectativa suscitada pela instrução de se ter que traduzir o texto futuramente, aponta que, em boa medida, uma pré-tradução provavelmente é incorporada à leitura de um texto assim que este é tomado como um texto-fonte a ser traduzido.

O aumento da duração da tarefa das Tarefas 1 e 2 para a Tarefa 3 é explicado pela solicitação de uma tradução oral do texto imediatamente após a leitura de cada sintagma ou sentença. Todos os participantes compreenderam que uma atividade de tradução à prima vista 
não permite que o tradutor tenha tempo de ler o texto completo antes de iniciar a produção da tradução oral. Apesar de a velocidade de leitura ser controlada pelo tradutor, diferentemente do que ocorre na tradução simultânea, ainda assim a tradução à prima vista introduz um elemento de pressão de tempo semelhante àquele da tradução simultânea, porque os ouvintes esperam que o produto seja apresentado em uma fala razoavelmente fluida.

O aumento da duração da Tarefa 3 para a 4 dá margem a diversas questões que não podem ser respondidas aqui. Por exemplo, não há dúvida de que nossos participantes eram todos capazes de pronunciar palavras mais rápido do que de digitá-las, mas não medimos essa diferença, que, acreditamos, dá conta apenas de uma pequena parte da diferença observada na duração da tarefa. Quando os participantes digitaram na Tarefa 4, sua velocidade de produção foi, muitas vezes, em torno de $60 \%$ da velocidade de fala na Tarefa 3, mas as pausas com que interrompiam a digitação eram muito mais longas do que as pausas realizadas na tradução oral na Tarefa 3. Isso pode ter ocorrido porque a tradução escrita é tipicamente associada a um alto nível de perfeição textual de acordo com os padrões da língua-alvo e a um alto nível de precisão na forma como se representa o significado do texto-fonte. Mesmo os tradutores não tendo tido acesso a apoios externos (de dicionários ou fontes na internet), é possível que o tempo adicional tenha sido investido na otimização da qualidade da tradução. No atual contexto, no entanto, esse potencial aumento da qualidade não foi avaliado. Ao investigarmos as diferenças na atenção visual, estávamos prioritariamente interessados em identificar diferenças causadas pelos propósitos de leitura e/ou pelo processamento concomitante ao à leitura.

\subsection{Número de fixações}

A simples instrução para ler um texto com o objetivo de traduzi-lo posteriormente causou um aumento significativo no número de fixações e, seguindo a hipótese olho-mente de Just et al. (1980, p. 330-331), um aumento na atividade de processamento, em comparação com a situação em que a instrução consistia em ler um texto para compreensão.

Ao contrário do que esperávamos, não houve evidência clara nos dados da Tarefa 2 de que as fixações se concentraram em determinadas áreas que estavam sendo pré-traduzidas durante a leitura (possíveis exemplos na representação do olhar mostrada na Figura 2 seriam "jeer" em "cheer or jeer" e "the Commons"). Parece mais que as instruções da Tarefa 2 desencadearam uma leitura mais lenta e, talvez, mais cuidadosa, responsável pela ocorrência de fixações mais densas ao longo de todo o texto. Já que, na Tarefa 2, os participantes não 
traduziram de fato o texto que leram "com o objetivo de traduzi-lo posteriormente", não foi possível comparar detalhes de suas leituras na Tarefa 2 e na Tarefa 4, na qual traduziram um texto diferente. O que foi possível observar foi que todos os 12 participantes apresentaram mais fixações na Tarefa 2 do que na 1 e que o aumento das fixações em comparação com a Tarefa 1 parece estar distribuído uniformemente ao longo de todo o texto em vez de se concentrar em pontos problemáticos que esperávamos que causariam problemas de tradução.

A solicitação de uma tradução oral na Tarefa 3 suscitou uma grande mudança no comportamento do movimento ocular dos participantes devido à necessidade não só de compreender o texto, mas também de monitorar o progresso da tradução. Na atividade de tradução à prima vista, foram necessárias fixações adicionais porque foi preciso que os olhos, para além de fornecerem ao cérebro insumos para a construção de significados, também lhe provessem informações de monitoramento em tempo real sobre quais partes do texto já tinham sido contempladas na produção oral e quais elementos ainda precisavam ser processados. O movimento ocular adicional foi causado pela necessidade de assegurar um gerenciamento (coordenação) da compreensão e da produção textual. Foi necessária essa atividade adicional do olhar no texto para garantir que as informações representadas no fluxo de produção oral do participante correspondiam dinamicamente à sequência de caracteres do texto na tela. Além disso, a solicitação de produzir uma tradução oral completa do texto (em contraste com a Tarefa 2) levou os participantes a relerem o texto que já haviam compreendido perfeitamente, mas para o qual não conseguiram produzir imediatamente uma tradução adequada. Isso levou os participantes a repetidamente realizarem fixações regressivas em palavras que já haviam sido fixadas (e, presumidamente, completamente compreendias); porém, as regressões foram, ao que parece, consideradas necessárias para garantir que todas as palavras e significados associados tinham sido produzidos na tradução oral.

A principal causa do enorme aumento no número de fixações na Tarefa 4 foi que, nesse caso, diferentemente do que ocorrera nas Tarefas 1 a 3, os olhos dos participantes estavam lendo e monitorando dois textos: não apenas um texto-fonte, como nas Tarefas 1 a 3, mas também as traduções emergentes do texto (para o dinamarquês). O referido aumento nas fixações na área do texto-fonte na Tarefa 4 foi de quase $40 \%$ em relação à Tarefa 3 . Parte desse aumento substancial pode, sem dúvida, ser atribuído aos hábitos de trabalho mais lentos e meticulosos tradicionalmente associados à tradução. Também é provável que o acréscimo de 
outro canal de processamento tenda a fragmentar o processamento concomitante dos insumos em segmentos menores.

No entanto, observamos que grande parte do aumento no número de fixações foi causada pela desorientação visual resultante da necessidade do tradutor de mudar constantemente sua atenção visual entre dois textos. Apesar de todos os nossos participantes possuírem boa habilidade de digitação, nossos registros de seus movimentos oculares mostraram claramente que todos, incluindo os verdadeiros digitadores, monitoraram sua digitação visualmente, seja olhando ocasionalmente para o teclado ou para o texto emergente na tela. Nenhum participante digitou o texto-alvo enquanto olhava exclusivamente para o texto-fonte. Isso significa que todos os participantes realizaram uma quantidade considerável de transições entre os dois textos e, como consequência, durante essas transições, os olhos frequentemente não voltavam para a palavra-alvo ideal, mas sim para a área-alvo, de forma que certa quantidade de releitura era necessária antes de se localizar a palavra ou sintagmaalvo. Cabe sublinhar, todavia, que estamos simplesmente apontando para o fenômeno com base no número geral de fixações; outros estudos são necessários para determinar a extensão exata e a natureza potencialmente onerosa de tais esforços de reorientação.

De acordo com a nossa interpretação, a causa do aumento no número de fixações foi o monitoramento visual do texto, necessário como meio de controlar a produção textual oral paralela (como na tradução à prima vista) ou como meio de gerenciar e controlar a produção concomitante do texto escrito (como na Tarefa 4).

\subsection{Duração do olhar}

Talvez não seja surpresa que a duração do olhar tenha sido relativamente maior nas Tarefas 1 e 3 do que na Tarefa 2. As Tarefas 1 e 3 são tarefas realizadas "de olhos bem abertos", enquanto a Tarefa 2 pode ter levado alguns participantes a, ocasionalmente, desviar o olhar ou mesmo fechar os olhos durante a reflexão sobre um problema de tradução em potencial.

A principal diferença na distribuição da duração do olhar entre os grupos foi em relação à atenção visual destinada à área do texto-fonte e à área do texto-alvo. Corroborando resultados anteriores (cf. JAKOBSEN, 2002, traduzido neste volume), observamos que os profissionais dedicaram duas vezes mais tempo aos próprios textos do que ao texto-fonte. Trata-se de uma evidência de que os tradutores profissionais geralmente investem muito mais esforço na revisão final de suas traduções do que os estudantes de tradução. É também um 
reflexo provável de que os estudantes de tradução têm mais dificuldade com a compreensão do texto-fonte na L2 do que os profissionais.

\subsection{Duração das fixações}

As fixações durante a leitura - seja para compreensão (Tarefa 1), para uma potencial tradução subsequente (Tarefa 2) ou para a compreensão do texto-fonte no âmbito de uma atividade de tradução escrita (Tarefa 4) - foram curtas (de $205 \mathrm{~ms}$ a $218 \mathrm{~ms}$ ), no geral. Contudo, as fixações na Tarefa 3 e na área do texto-alvo (na Tarefa 4) foram geralmente mais longas (de $235 \mathrm{~ms}$ a $259 \mathrm{~ms}$ ). Isso indica que o monitoramento da leitura durante a realização de uma tarefa concomitante (de falar ou digitar uma tradução) leva a um maior número e a uma maior duração média das fixações, de forma que a duração total do olhar no texto aumenta a partir desses dois parâmetros.

Apesar do provável efeito de pré-ativação (priming) decorrente da semelhança lexical e de assunto entre os quatro textos, que em tese resultaria em um menor número e uma menor duração das fixações, observamos o oposto. Tanto o número de fixações como a duração média das fixações foram maiores nas Tarefas 3 e 4 (na área do texto-fonte) do que nas Tarefas 1 e 2. Evidentemente, os aumentos da Tarefa 1 para a 2, da Tarefa 2 para a 3 e assim por diante estiveram relacionados com a tarefa. As durações das fixações foram iguais nas Tarefas 1 e 2, mas maiores tanto na Tarefa 3 quanto na Tarefa 4 (área do texto-fonte) porque essas duas tarefas exigiram um tipo diferente de leitura, que inclui o monitoramento visual do progresso da tradução.

\subsection{Transições (Tarefa 4)}

Para o grupo de profissionais, o número médio de transições foi de 190 e, para o grupo de estudantes, 259 (ou 367 considerando os outliers). Todas essas transições são parte do processo de alinhamento e monitoramento que caracteriza a tradução, mas cada transição requer que o olho despenda certo tempo para encontrar e retornar ao ponto do texto de onde se saiu anteriormente. Esse processo, que envolve transições de um texto para o outro a cada $3 \mathrm{~s}$ ou $4 \mathrm{~s}$, leva os tradutores, frequentemente, a fixar e reler várias palavras antes de chegarem ao segmento-alvo pretendido. Não há dúvida de que esse aumento acentuado no número de fixações na Tarefa 4 foi causado principalmente pelo fato de, nessa tarefa, haver dois textos 
visuais de que se ocupar, mas, ao menos em parte, também o foi pela confusão e desorientação causada pela transição frequente entre os dois textos.

\section{Conclusão}

As diferenças entre as Tarefas 1 e 2 mostraram que o propósito da leitura teve um efeito claro sobre os movimentos oculares e sobre a duração do olhar. A instrução de ler um texto com o objetivo de traduzi-lo posteriormente levou os participantes a procederem a um processamento considerável que superou aquele decorrente da instrução de ler o texto para compreensão. No geral, os aumentos nos números de fixações da primeira para a última tarefa do experimento foram estatisticamente significativos.

A Tarefa 3 demandou mais tempo e mais fixações e foi mais cognitivamente dispendiosa do que as tarefas anteriores por duas razões. Em primeiro lugar, teve de ser produzida uma tradução oral do texto-fonte exibido na tela. Em segundo lugar, à medida que essa tradução estava sendo proferida, os olhos estavam trabalhando para coordenar processos de compreensão e tradução enquanto se lia o texto-fonte e se monitoravam as partes do texto que já tinham sido processadas e aquelas que ainda estavam esperando para serem traduzidas.

Também podemos tirar uma conclusão principal com base nos dados da Tarefa 4. Mais especificamente, uma razão para a tradução escrita ter sido mais lenta foi o fato de que envolveu uma leitura muito fragmentada, com transições frequentes entre o texto-fonte e o texto-alvo.

Olhando para trás, acreditamos que deveríamos ter incluído no experimento uma tarefa para a qual os participantes seriam simplesmente instruídos a ler um texto em voz alta. Essa tarefa teria possibilitado sabermos mais sobre quanto movimento ocular adicional é ensejado por uma atividade de produção oral concomitante que não envolve tradução. Também teria possibilitado investigar quaisquer diferenças decorrentes da tradução solicitada na Tarefa 3.

Portanto, há mais trabalho a ser realizado até podermos tornar nossos sonhos realidade, ou seja, até podermos alcançar nosso objetivo prático de reformular práticas pedagógicas que sejam condizentes com o nosso entendimento melhorado acerca da tradução e concretizar nossa expectativa de desenvolver ferramentas inteligentes de suporte para tradutores. O que precisamos, acima de tudo, é explorar mais o maior desafio de pesquisa que temos à nossa frente: entender e modelar não apenas a forma como os tradutores leem, mas todo a maneira pela qual o cérebro humano bilíngue consegue gerenciar e coordenar os complexos processos a que nos referimos como tradução. 


\section{Referências}

BERTRAM, R.; HYÖNA, J. The length of a complex word modifies the role of morphological structure: evidence from eye movements when reading short and long Finnish compounds. Journal of Memory and Language, v. 48, p. 615-634, 2003.

FRISSON, S.; RAYNER, K.; PICKERING, M. J. Effects of contextual predictability and transitional probability on eye movements during reading. Journal of Experimental Psychology: Learning, Memory and Cognition, v. 31, p. 862-877, 1999.

HYÖNA, J.; RADACH, R.; DEUBEL, H. The mind's eye. Cognitive and applied aspects of eye movement research. Amsterdã: Elsevier, 2003.

JAKOBSEN A. L. Translation drafting by professional translators and by translation students. Traducción \& Communicación, v. 3, p. 89-103, 2002.

JUHASZ, B. J.; RAYNER, K. Investigating the effects of a set of intercorrelated variables on eye fixation durations in reading. Journal of Experimental Psychology: Learning, Memory and Cognition, v. 29, p. 1312-1318, 2003.

JUST, M. A.; CARPENTER, P.A. A theory of reading: from eye fixations to comprehension. Psychological Review, v. 87, p. 329-354, 1980.

KLIEGL, R. et al. Length, frequency, and predictability effects of words on eye movements in reading. European Journal of Cognitive Psychology, v. 16, p. 262-284, 2004.

RADACH, R.; KENNEDY, A.; RAYNER, K. Eye movements and information processing during reading. Hove: Psychology Press, 2004.

RAYNER, K. Eye movements in reading and information processing: 20 years of research. Psychological Bulletin, v. 124, p. 372-422, 1998.

RAYNER, K.; DUFFY, S. A. Lexical complexity and fixation times in reading: effects of word frequency, verb complexity, and lexical ambiguity. Memory and Cognition, v. 14, p. 191-201, 1986.

RAYNER, K.; POLLATSEK. A. The psychology of reading. Englewood Cliffs, N.J.: Prentice Hall, 1989.

WILLIAMS, R. S.; MORRIS, R. K. Eye movements, word familiarity, and vocabulary acquisition. European Journal of Cognitive Psychology, v. 16, p. 312-339, 2004. 


\section{Apêndice A}

\section{Historic day as Blair surrenders power and Brown finally moves into No 10.}

Tony Blair surrendered on his own terms today as Gordon Brown ushered in a new radical era of change. Ending a decade of relentless controversy, wars and even a police inquiry, Labour's longest-serving Prime Minister was set to stroll out of No 10 with his head held high. It is also the day Mr Blair is expected to announce that he is turning his back on British politics for good to take up a job as special envoy to the Middle East. He is poised to resign as an MP on the same day he steps down as Prime Minister - triggering a by-election in his constituency of Sedgefield, which could be held as early as July 19.

His decision to stand down after 24 years in Parliament will allow him to 'throw himself' into the role as the international community's key peacemaker in the Middle East, his close allies said. Today at Downing Street, crowds of well-wishers, and protesters were gathering in Whitehall to watch, cheer or jeer his final progress from Downing Street to the Commons for his final Prime Minister's Questions.

http://www.dailymail.co.uk

Última atualização: 27/06/2007 às 9:28h

Número de palavras: 197

Número de caracteres com espaço: 1.102

\section{Finally, Blair exits the stage}

Tony Blair will say farewell to Downing Street and domestic politics today, bringing to an end a remarkable decade in power which began with extraordinarily high hopes but ended with opinion divided over his legacy to the country. After his last appearance at the dispatch box at Prime Minister's questions Mr Blair will return to Downing Street to make an emotional farewell to his staff, some of whom have been with him since he became Leader of the Opposition in the heady days of 1994 and the birth of New Labour. 
Mr Blair, Labour's most successful leader after an unprecedented three election victories, making him - alongside Margaret Thatcher - one of the dominant political figures since the war, will drive up The Mall to Buckingham Palace with his wife Cherie to tender his resignation to the Queen. In contrast to his arrival as Prime Minister in May 1997 when Downing Street was lined with handpicked Labour Party members cheering, and waving Union flags, Mr Blair will make a low-key exit. Today it will be photographers, not supporters, recording his reluctant departure.

http://www.telegraph.co.uk

Última atualização: 27/06/2007 às 8:30h

Número de palavras: 187

Número de caracteres com espaço: 1.115

\section{Blair exits British politics as new era begins with a Tory defection}

A new political order in Britain will take shape this afternoon when Tony Blair flies to his Sedgefield constituency to resign from parliament with immediate effect, and Gordon Brown enters No 10 to prepare a shakeup of government which will see at least six ministers quit the cabinet. Mr Brown's allies said the new ministerial line-up would be deliberately inclusive, and not settle scores with Mr Blair's supporters. Mr Blair had planned to keep the decision to quit as an MP secret until after his $318^{\text {th }}$ and final prime minister's questions at noon today. But news leaked that his local party was being called to an extraordinary meeting to be addressed tonight by Mr Blair.

Two of his aides in No 10 are expected to join him in his new life as a Middle East envoy. If, as expected, the role is confirmed today, Mr Blair will resign as an MP, triggering a byelection which may take place as early as July. His departure from parliament means his earnings from the lecture circuit will be kept from the register of members' interests.

http://politics.guardian.co.uk

Quarta-feira, 27/06/2007

Número de palavras: 194

Número de caracteres com espaço: 1.106 


\section{Blair may quit as MP if he gets role in Middle East}

Tony Blair will stand down as Labour MP for Sedgefield if, as expected, he is appointed as a special international envoy to the Middle East today. The Prime Minister's move will trigger a by-election in the County Durham constituency he has represented since 1983, where he has a majority of 18,449 .

On his last full day as Prime Minister, Mr Blair made clear he was keen to be appointed as an envoy for the Quartet - the US, the EU, the UN and Russia. "I think that anybody who cares about greater peace and stability in the world knows that a lasting and enduring resolution of the Israeli-Palestinian issue is essential." he said.

He was speaking at a joint press conference with Arnold Schwarzenegger, the Governor of California. Mr Blair was in a relaxed mood, but did not want to upset his successor. Asked if he had advice for the new Prime Minister, he replied: "No ... because he is perfectly capable of doing the job on his own, thank you."

US president George Bush last night paid tribute to the "very talented" Tony Blair. http://www.independent.co.uk

Quarta-feira, 27/06/2007

Número de palavras: 196

Número de caracteres com espaço: 1.082 